\title{
The robust counterpart open capacitated vehicle routing problem with time windows on waste transport problems
}

\author{
Evi Yuliza ${ }^{1}$, Fitri Maya Puspita², Siti Suzlin Supadi ${ }^{3}$ \\ ${ }^{1,2}$ Department of Mathematics, Faculty of Mathematics and Natural Sciences, University of Sriwijaya, Indonesia \\ ${ }^{3}$ Institute of Mathematical Sciences, Faculty of Science, University of Malaya, Malaysia
}

\begin{tabular}{l} 
Article Info \\
\hline Article history: \\
Received Jan 27, 2020 \\
Revised Mar 5, 2020 \\
Accepted Apr 2, 2020 \\
\hline
\end{tabular}

Keywords:

GAMS

LINGO

RCOCVRP model

Soft time windows

Waste transportation

\begin{abstract}
The optimum route for garbage transport vehicles is restricted by vehicle capacity and time windows that the garbage transport vehicle starts at the origin and does not return to the origin. The problem of transporting waste routes is a robust optimization problem where the amount of waste in an area and travel time is uncertain. In the real world, traffic jams and vehicle engine damage can cause delays. This paper proposes the robust counterpart open capacitated vehicle routing problem (denoted by RCOCVRP) with soft time windows model. The aim of RCOCVRP with soft time windows model is to find schedule and optimum route of transporting waste. This model calculation uses LINGO software and GAMS software. Finally for the evaluation of the RCOCVRP model with soft time windows on the proposed waste transportation problem is conducted so that it hasa feasible solution.
\end{abstract}

This is an open access article under the CC BY-SA license.

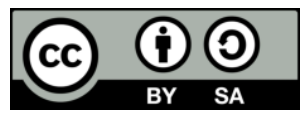

Corresponding Author:

Evi Yuliza,

Faculty of Mathematics and Natural Sciences,

University of Sriwijaya,

Jln. Raya Palembang-Prabumulih, KM 32 Inderalaya Ogan Ilir 30662 South Sumatera, Indonesia.

Email: evibc3@yahoo.com

\section{INTRODUCTION}

The vehicle routing problem (VRP) is a combinatorial optimization problem that has developed in the fields of transportation [1], distribution, environment [2] dan economy [3]. Vehicles that serve several customers are limited by the capacity of the vehicle called capacitated vehicle routing problem (CVRP) [4, 5]. The aims of CVRP are to find optimum route for every vehicle to serve a set customers based on a single depot and to serve a set of customers under the constraints as such as each route begins and ends at the depot where each customer is visited exactly once and the total demand of each route does not exceed the capacity of the vehicle [6-8]. Some researchers have discussed VRP and CVRP on the problem of collecting waste, modeling and completing models using heuristics[9-10]. Vehicle routes on VRP begin at the starting point and do not end at the starting point. This VRP is an open vehicle routing problem (OVRP) [11-13]. VRP which is limited to windows time intervals is called vehicle routing problem time windows (VRPTW) [14]. VRPTW can aim to optimize vehicle routes and determine scheduling [15].

Robust optimization is an optimization problem approach for data that has uncertainly. Sungur et al. [16] and Sun [17] discuss robust optimization of the problem of vehicle routes with demand uncertainly which is called roubust capacitated vehicle routing problem (RCVRP). Robust optimization research has increased development in vehicle route problems, for example in the fields of transportation and distribution [18-19]. Optimization robust of VRP with time windows (RVRPTW) is a combination of RVRP by considering time windows [18, 20-24]. Time windows can be soft time windows which means 
vehicles can violate every time windows on VRP $[25,26]$. The RVRPTW is generalization of vehicle routing problem with time windows [18]. The aim of this model is to find the minimum total cost and the minimum total distance of a vehicle through several customer locations so that each route starts and ends at a common location and some side constraints are satisfied. Vehicle routes and delivery times are affected by delays and must be taken into account. For example, weather problems, traffic jams and vehicle mechanical problems. OVRP that considers demand uncertainly is robust open vehicle routing problem (ROVRP) [27]. Research on robust counterpart open capacitated vehicle routing problem (RCOCVRP) has been performed on the problem of transporting waste and the solution of this model using the branch and bound method [28-29]. Puspita et al. [30] discussed the RCOCVRP model with demand on the problem of transporting waste in Sematang Borang District. The proposed RCOCVRP model [28-30] optimizes the route to the problem of transporting waste and does not take into account the time windows limit. In the real world, the process of transporting waste sometimes experiences delays such as traffic jams and vehicle engine damage.

The motivation of this study is to describe the garbage transportation system in one of the districts in the city of Palembang, namely Ilir Timur I District. This research developed an existing robust optimization model. The purpose of our paper is to ensure that Palembang Office of Environment and Hygiene (POEH) will adopt a system that is built so that the garbage transportation management done by POEH is more efficient with the model we offer. The robust counterpart open capacitated vehicle routing problem (RCOCVRP) with soft time windows concept is the development of existing robust optimization by adding vehicle capacity and time windows variables. This study proposes a robust optimization model that focuses on the RCOCVRP model with soft time windows to optimize vehicle routes. This model is based on the RCVRP model [31], RVRPTW [20] dan ROVRP [27]. RCOCVRP model with soft time windows is simulated on the problem of transporting waste in Ilir Timur I District, Palembang to determine route optimization and the scheduling of waste transportation. Thus, services for each customer can be satisfied and the vehicle route does not return to the initial location with the volume limit of the transported waste not exceeding the vehicle's capacity and time windows.

\section{DESCRIPTION OF THE PROBLEM}

Garbage as one of the problems in urban areas. Most of the rubbish is contributed from households, traditional markets, shops, offices and other city residents'activites. Accumulation of waste in densely populated areas, traditional markets, shops and offices will cause environmental problems. POEH carries out waste transportation activities in all district. Each sub-district has a temporary disposal site (TDS) as a temporary landfill that is transported by POEH waste transportation vehicles. Ilir Timur I sub-district is one of the sub-districts in the city of Palembang. Every garbage transport officer is assigned to an area called a work area. A garbage transport vehicle transports waste at each TDS located in a work area and ends at the final disposal site (FDS). The garbage transport officer who is in charge of transporting garbage at the TDS that has a waste volume of $6 \mathrm{~m}^{3}$ (container), usually the waste is immediately disposed of at the Sukawinatan FDS. According to POEH, TDS consists of POEH TDS, independent TDS and illegal TDS. All the waste in the POEH TDS, the independent TDS and the illegal TDS is transported by the POEH waste transport vehicle. This is done to create a clean and healthy city environment. Garbage transport vehicles that visit each TDS are limited by vehicle capacity.

The volume of waste at a TDS is uncertain, so the problem of transporting waste is a robust optimization problem [16, 17]. Garbage transport vehicles start departing at a TDS as a starting point and do not return to that point so the problem of garbage transportation routes is called the open vehicle routing problem [27]. When the process of transporting waste from TDS to $i$ to TDS to $j$, sometimes the garbage transport vehicle experiences delays [20]. The delay was caused by congestion, engine damage and running out of fuel. Therefore, the arrival time of garbage transport vehicles often experiences delays. The research data was obtained from the POEH in the form of garbage transportation route data in the city of Palembang on September, 2019. This research will optimize the route and scheduling of waste transportation in the district of Ilir Timur I, Palembang. Several conditions need to be limited for this research as as follows:

- Types of garbage transport vehicles are dump trucks and containers.

- The capacity of a dump truck has a capacity of 6-8 tons and the container has a capacity of 3-4 tons.

- The working hours of the garbage carrier consists of two transportation processes which are 06:00-10:00 hours and 16:00-20:00 hours.

- It is assumed that the time to put garbage into the vehicle and remove it from the vehicle is about 10 to 15 minutes.

- Waste transported from each TDS is disposed of at FDS Sukawinatan.

- The speed of the garbage transport vehicle is assumed to be $40 \mathrm{~km} / \mathrm{hour}$. 


\section{RESEARCH METHOD}

RCOCVRP solutions with soft time windows model are search using LINGO software and GAMS software. The steps of the research are structured as follows:

- Desciption of the data. This research data includes vehicle capacity, distance of each TDS to TDS, distance of each TDS to FDS, travel time, volume of waste at each TDS and time windows.

- Identify variables and parameters.

- Formulate the RCOCVRP with time windows model.

- Solve the RCOCVRP with time windows model using the branch and bound method and the branch and cut method.

- Computational calculations using LINGO 13.0 and GAMS 25.1.1 software.

In this study, we use procedure that is shown in Figure 1.

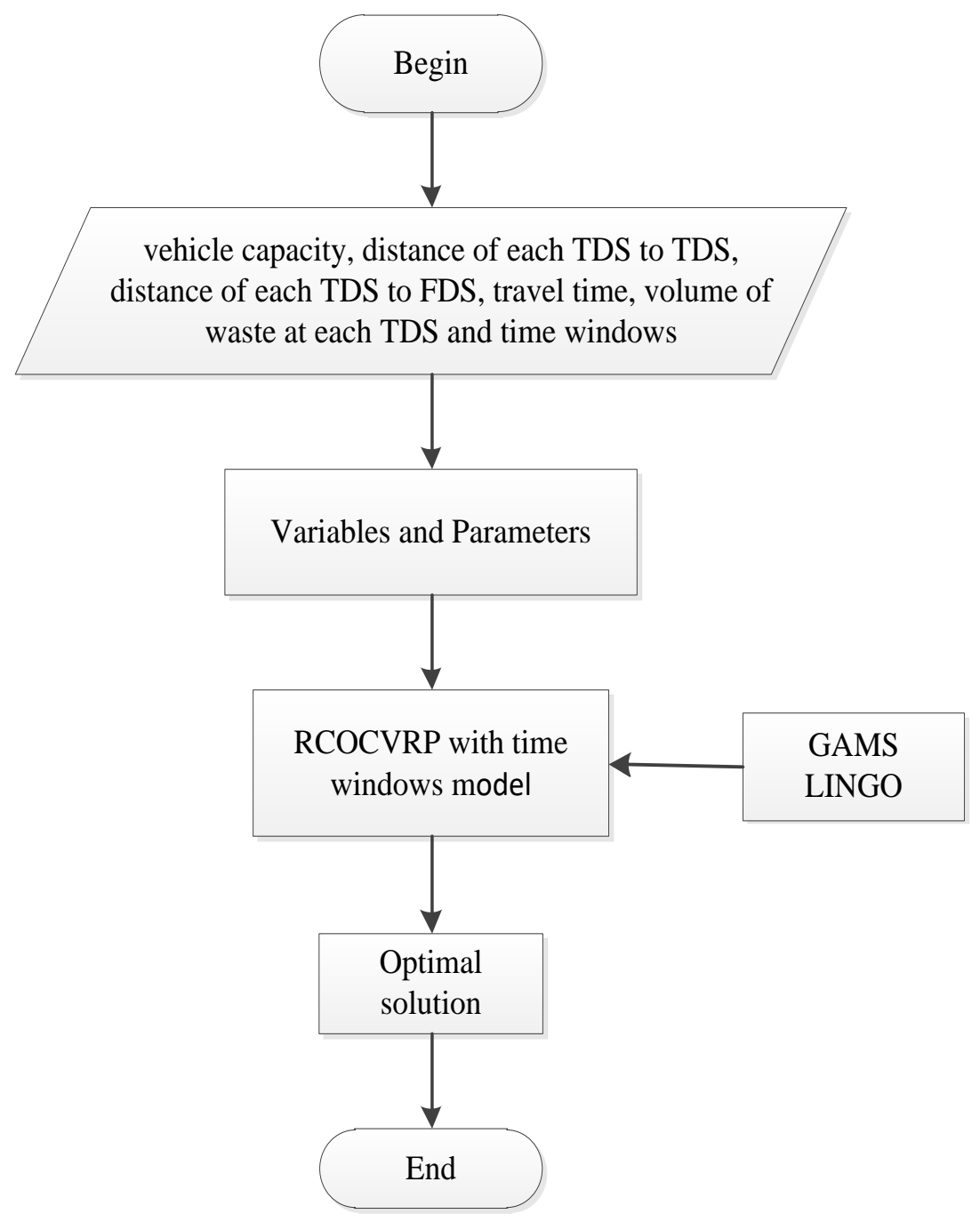

Figure 1. Procedure for solving the RCOCVRP model with a soft time window

\section{RESULTS AND DISCUSSION}

RCOCVP model with soft time windows that have been formed, is simulated on the problem of waste transportation in Ilir Timur I District, Palembang. The problem of transporting waste in the district Ilir Timur I consists of 12 working areas with varied number of TDS as displayed in Table 1. In Table 1 the garbage transport area in Ilir Timur I sub-district consists of 12 working areas. Each working area has several TDS consisting of waste volume and time windows. 
Table 1. Data for waste transporting problem

\begin{tabular}{|c|c|c|c|c|}
\hline Working area & Total TDS & Vehicle Type & Garbage Volume (kg) & Time windows \\
\hline 1 & 2 & container & $\begin{array}{l}4500 \\
2000\end{array}$ & $\begin{array}{c}7,8] \\
{[8.5,10]} \\
{[10.5,11]}\end{array}$ \\
\hline 2 & 5 & dump truck & $\begin{array}{l}4500 \\
2000 \\
4000 \\
4500 \\
2000\end{array}$ & $\begin{array}{c}{[7,7.5]} \\
{[7.5,8]} \\
{[8.5,9]} \\
{[9,9.5]} \\
{[10,10.5]} \\
{[10.5,11]} \\
{[7,7.3]}\end{array}$ \\
\hline 3 & 8 & dump truck & $\begin{array}{l}4500 \\
2000 \\
4000 \\
4500 \\
2000 \\
4000 \\
4500\end{array}$ & $\begin{array}{c}{[7.3,7.6]} \\
{[7.6,8]} \\
{[8.3,8.6]} \\
{[8.6,9]} \\
] 9.3,9.6] \\
{[9.6,10]} \\
{[10,10.3]} \\
{[10.6,11]}\end{array}$ \\
\hline 4 & 8 & dump truck & $\begin{array}{l}4500 \\
2000 \\
4000 \\
4500 \\
2000 \\
4000 \\
4000 \\
4500\end{array}$ & $\begin{array}{c}{[7,7.3]} \\
{[7.3,7.6]} \\
{[7.6,8]} \\
{[8.3,8.6]} \\
{[8.6,9]} \\
{[9.3,9.6]} \\
{[9.6,10]} \\
{[10.3,10.6]} \\
{[10.6,11]}\end{array}$ \\
\hline 5 & 3 & dump truck & $\begin{array}{l}4500 \\
2000 \\
4000\end{array}$ & $\begin{array}{c}{[1,8]} \\
{[8.3,9]} \\
{[9.2,10]} \\
{[10,11]}\end{array}$ \\
\hline 6 & 4 & dump truck & $\begin{array}{l}4500 \\
2000 \\
4000 \\
4500\end{array}$ & $\begin{array}{c}{[7,7.5]} \\
{[7.6,8]} \\
{[8,9]} \\
{[9.2,10]} \\
{[10,11]}\end{array}$ \\
\hline 7 & 1 & Container & 4500 & $\begin{array}{c}{[7,9]} \\
{[9,11]}\end{array}$ \\
\hline 8 & 2 & Container & $\begin{array}{l}4500 \\
2000\end{array}$ & $\begin{array}{c}{[7,8]} \\
{[8.3,8.6]} \\
{[10,11]}\end{array}$ \\
\hline 9 & 5 & dump truck & $\begin{array}{l}4500 \\
2000 \\
4000 \\
4500 \\
2000\end{array}$ & $\begin{array}{c}{[7,7.6]} \\
{[7.3,8]} \\
{[8,8.4]} \\
{[8.5,9]} \\
{[9.2,10]} \\
{[10.2,11]}\end{array}$ \\
\hline 10 & 9 & dump truck & $\begin{array}{l}4500 \\
2000 \\
4000 \\
4500 \\
2000 \\
4000 \\
4000 \\
4500 \\
2000\end{array}$ & $\begin{array}{c}{[7,7.2]} \\
{[7.2,7.5]} \\
{[7.5,8]} \\
{[8,8.4]} \\
{[8.4,8.6]} \\
{[8.6,9]} \\
{[9,9.4]} \\
{[9.4,9.6]} \\
{[9.6,10]} \\
{[10.3,11]}\end{array}$ \\
\hline 11 & 2 & Container & $\begin{array}{l}4500 \\
2000\end{array}$ & $\begin{array}{c}{[7,8]} \\
{[8,9]} \\
{[10,11]}\end{array}$ \\
\hline 12 & 6 & dump truck & $\begin{array}{l}4500 \\
2000 \\
4000 \\
4500 \\
2000 \\
4000\end{array}$ & $\begin{array}{c}{[7,7.2]} \\
{[7.2,7.6]} \\
{[7.6,8]} \\
{[8.4,8.6]} \\
{[9,9.5]} \\
{[9.5,10]} \\
{[10.6,11]}\end{array}$ \\
\hline
\end{tabular}




\subsection{A mathematical formulation of the RCOCVRP with soft time windows model}

The RCOCVRP with soft time windows model is a robust optimization problem as a development of the RCVRP, ROVRP and RCVRPTW models. RCOCVRP model with soft time windows is solved by an exact approach so that a good solution is obtained in accordance with the real world. RCOCVRP model with soft time windows aims to minimize vehicle distance and vehicle route scheduling. This RCOCVRP model with soft time windows is simulated on the problem of transporting waste in Ilir Timur I sub-district, Palembang. Calculation of RCOCVRP model with soft time windows based on LINGO 13.0 software and GAMS software. LINGO is a special software package for solving mathematic programming problem which built a language for estabilishing the optimization model [32, 33]. The GAMS is a most powerful optimizer tool which is used for formulating, solving and analysing an optimization problem. GAMS is used to solve linear, non linear and mix integer-based optimization problem. There are number of solver in GAMS such as CONOPT, CPLEX, DICOPT and KNITRO [34, 35]. This research uses CPLEX solver.

We are given a directed graph $G=(V, A)$ with $V=\{1,2,3, \ldots, n+1\}$ as a set of nodes and $A=$ $\{(i, j) \mid i=0,1,2, \ldots, n+1$ dan $j=1,2, \ldots, n+1, i \neq j\}$ as a the set of arcs, where node $1,2, \ldots, n$ represent each customers and node $n+1$ represents the depot. $A^{k}$ represents the set of all arcs by vehicle $k, A^{k} \subseteq A$ with $K=\{1,2,3, \ldots, k\}$. We denoted $N, N \subset V$ by the set of nodes that are not origin $(o)$ and destination $(d)$. $T$ represents the set of time windows at each customers, $T=\left\{\left[a_{i}, b_{i}\right] \mid i \in V\right\} . \operatorname{ext}(T)$ represents the set of all extreme points on $T$. RCOCVRP with soft time windows model as follows:

$$
\min Z=\sum_{k \in K} \sum_{\substack{(i, j) \in A^{k} \\ i \neq j}} c_{i j}^{k} x_{i j}^{k}
$$

subject to

$$
\begin{aligned}
& \sum_{j \in V, i \neq j} x_{i j}^{k}=1, \forall i \in V, k \in K \\
& \sum_{j \in V, i \neq j} x_{j i}^{k}=1, \forall i \in V, k \in K \\
& q_{i} \leq y_{i} \leq Q, \forall i \in V \backslash\{n+1\} \\
& y_{i} \leq Q, i=n+1 \\
& y_{i}-y_{j}+Q x_{i j} \leq Q-q_{j}, \forall(i, j) \in A^{k}, k \in K \\
& \sum_{j \in N ;(j, i) \in A^{k} ; j \neq i} x_{j i}^{k}-\sum_{j \in N ;(i, j) \in A^{k} ; i \neq j} x_{i j}^{k}=\left\{\begin{array}{c}
-1, i=o \\
1, i=d \\
0, \text { the others }
\end{array}\right. \\
& a_{i} \leq t_{i} \leq b_{i}, i \in V, t \in \operatorname{ext}(T) \\
& t_{i}-t_{j}+\left(b_{i}+t_{i j}^{k}-a_{j}\right) x_{i j}^{k} \leq b_{i}-a_{j},(i, j) \in A^{k}, k \in K \\
& x_{i j}^{k} \in\{0,1\},(i, j) \in A^{k}, k \in K
\end{aligned}
$$

The objective function (1) is to minimize the total distance of vehicle. Constraints (2) and constraints (3) ensure that all $i \in V$ are served exactly one. The constraint given in (4) and (5) are the capacity limit constraints that limit the upper and lower limits of $y$. Constraints (6) ensures that the solution contains no sub tours are cut off to destination, and that the vehicle load is a non-decreasing step function in accordance with the demand at each customers who are on the route of the vehicle. Constraints (7) are the flow conservation constraints for each vehicle. Constraints (8) guarantee time windows. Constraints (9) link routes and schedules, that is $t_{j}$ must be greater than or equal to $t_{i}+t_{i j}^{k}$ whenever vehicle $k$ travels from customer $i$ to customer $j$. Constrains (10) is the decision variables. The variables and the paramaters in the RCOCVRP with soft time windows model is as shown in Table 2 and Table 3. 
Table 2. Variables

\begin{tabular}{cc}
\hline Variable & Description \\
\hline$x_{i j}^{k}$ & a vehicle $k$ travels between TDS $i$ to $j$ \\
$t_{i}$ & Time arrived of the vehicle when serving TDS to $i$ \\
$t_{j}$ & Time arrived of the vehicle when serving TDS to $j$ \\
$y_{i}$ & Vehicle load when leaving TDS to $i$ \\
$y_{j}$ & Vehicle load when leaving TDS to $j$ \\
\hline
\end{tabular}

Table 3. Parameters

\begin{tabular}{cc}
\hline Parameter & Description \\
\hline$c_{i j}^{k}$ & distance from TDS $i$ to TDS $j$ by vehicle $k$ \\
$Q$ & vehicle capacity \\
$q_{i}$ & quantity of garbage transported at TDS to $i$ \\
$t_{i j}^{k}$ & travel time from TDS to $i$ to TDS to $j$ by vehicle $k$ \\
$a_{j}$ & the time when the vehicle left the TDS $i$ \\
$b_{i}$ & the time when the vehicle left the TDS $j$ \\
\hline
\end{tabular}

\subsection{Solution of model RCOCVRP with soft time windows}

The calculation of the RCOCOCVRP with soft time windows model on the garbage transporting problem is simulated in the working area 3. A mathematical formulation of RCOCVRP with soft time windows based on objective function (1) and constrant (2) to (10). The LINGO software settlement type uses the branch and bound method, obtained $x_{56}=x_{65}=0.667, x_{58}=x_{68}=x_{75}=x_{76}=x_{78}=0.333$ and objective value 35.67. Because there are non-integer decision variables, branching is done. Adding variables $x_{56} \leq 0, x_{36} \geq 1, x_{65} \geq 1$ and $x_{58} \geq 1$ to the model. GAMS software solver type uses CPLEX, obtained $x_{65}=x_{78}=0.583, x_{68}=x_{73}=0.417$ and objective value 35.9 . Because there are non-integer-valued variables, variabel $x_{65} \geq 1, x_{56} \leq 0, \leq, x_{36} \geq 1$ dan $x_{58} \geq 1$ are added to the model. The solution operated in LINGO and GAMS is shown in Table 4.

Table 4. Distance, route and time windows in the working area 3

\begin{tabular}{|c|c|c|c|}
\hline Distance $(\mathrm{km})$ & Route & Vehicle load (kg) & Arrived time \\
\hline \multirow{9}{*}{37.31} & \multirow{9}{*}{$\begin{array}{c}\text { TDS } 1-\text { TDS 4-TDS 3-TDS 6-TDS 5-DS 8- } \\
\text { TDS 7-FDS-TDS 2-FDS }\end{array}$} & 4500 & $07: 00$ \\
\hline & & 2000 & 07:03 \\
\hline & & 4000 & 08:00 \\
\hline & & 2500 & 08.03 \\
\hline & & 6000 & 09:00 \\
\hline & & 4000 & 09:03 \\
\hline & & 4000 & 10:00 \\
\hline & & 2500 & $10: 03$ \\
\hline & & 6000 & $11: 00$ \\
\hline
\end{tabular}

The solution of RCOCVRP model with soft time windows using LINGO has 12 iterations while using GAMS has 4 iterations. We can see from Table 4 that the RCOCVRP model with soft time windows in working area 3 has a feasible solution if the vehicle transporting garbage does not exceed the vehicle's capacity and satisfied the time windows. Overall in each work area also obtained feasible solutions.

\section{CONCLUSION}

GAMS software is more powerful optimizer tool than LINGO software for solving RCOCVRP models with soft time windows on the problem of transporting waste. A solution of the RCOCVRP with soft time windows model has a feasible solution if the vehicle load leaving the customer does not exceed or equal to the vehicle capacity and the time of arrival of the vehicle to $i$ earlier than the time window. Next research on the RCOCVRP model with soft time windows is suggested to consider the limitations of the number of crews and the solution of the RCOCVRP with soft time windows model with soft time windows can be solved by a heuristic approach.

\section{REFERENCES}

[1] K. E. L. Bouyahyiouy and A. Bellabdaoui, "An ant colony optimization algorithm for solving the full truckload vehicle routing problem with profit," in Conference: 2017 International Colloquium on Logistics and Supply Chain

The robust counterpart open capacitated vehicle routing problem with time windows on... (Evi Yuliza) 
Management (LOGISTIQUA), pp. 142-147, April 2017.

[2] J. Liu and Y. He, "A Clustering-Based Multiple Ant Colony System for the Waste Collection Vehicle Routing Problems," 2012 Fifth International Symposium on Computational Intelligence and Design, pp. 182-185, 2012.

[3] Y. Wang and T. A. Zhou, "An Optimization Model of Banking Outlets Integration Based on the Network Comprehensive Analysis," Bull. Electical Eng. Informatics, vol. 4, no. 3, pp. 248-256, Sep 2015.

[4] M. K. Jepsen, David, Pisingerm, "Branch-and-cut and Branch-and-Cut-and-Price Algorithms for Solving Vehicle Routing Problems," Technical University of Denmark (DTU), 2011.

[5] K. Braekers, K. Ramaekers, and I. Van Nieuwenhuyse, "The vehicle routing problem: State of the art classification and review," Comput. Ind. Eng., vol. 99, pp. 300-313, Sep 2016.

[6] G. Laporte, "What You Should Know about the Vehicle Routing Problem," Noval Res. Logist., vol. 54, no. 8, pp. 811-819, Dec 2007.

[7] Z. Borcinova, "Two models of the capacitated vehicle routing problem," Croat. Oper. Res. Rev., vol. 8, pp. 463-469, 2017.

[8] M. M. Tavakoli and A. Sami, "Particle Swarm Optimization in Solving Capacitated Vehicle Routing Problem," Bull. Electical Eng. Informatics, vol. 2, no. 4, pp. 252-257, Dec 2013.

[9] M. A. Hannan, et al., "Capacitated vehicle-routing problem model for scheduled solid waste collection and route optimization using PSO algorithm," Waste Manag., vol. 71, pp. 31-41, Jan 2018.

[10] N. A. Mat, A. M. Benjamin, and S. Abdul-Rahman, "Efficiency of Heuristic Algorithms in Solving Waste Collection Vehicle Routing," J. Soc. Sci. Res., no. 6, pp. 695-700, Dec 2018.

[11] A. D. López-Sánchez, et al., "A multi-start algorithm for a balanced real-world Open Vehicle Routing Problem," Eur. J. Oper. Res., vol. 238, no. 1, pp. 104-113, Oct 2014.

[12] J. Bauer and J. Lysgaard, "The offshore wind farm array cable layout problem: A planar open vehicle routing problem,” J. Oper. Res. Soc., vol. 66, no. 3, pp. 360-368, March 2015.

[13] R. Atefi, M. Salari, L. C. Coelho, and J. Renaud, "The open vehicle routing problem with decoupling points," Eur. J. Oper. Res., vol. 265, no. 1, pp. 316-327, Feb 2018.

[14] C. K. Heng, Q. C. Nguyen, and S. Jiang, "Application of Route Flexibility in Data-Starved Vehicle Routing Problem with Time Windows," IEEE, pp. 799-805, 2016.

[15] A. K. Ariyani, W. F. Mahmudy, and Y. P. Anggodo, "Hybrid Genetic Algorithms and Simulated Annealing for Multi-trip Vehicle Routing Problem with Time Windows," Int. J. Electr. Comput. Eng., vol. 8, no. 6, pp. 4713-4723, Dec 2018.

[16] I. Sungur, F. Ordóñez, and M. Dessouky, "A robust optimization approach for the capacitated vehicle routing problem with demand uncertainty," IIE Trans., vol. 40, no. 5, pp. 509-523, 2006.

[17] L. Sun and B. Wang, "Robust optimisation approach for vehicle routing problems with uncertainty," Math. Probl. Eng., vol. 2015, pp. 1-8, 2015.

[18] S. Braaten, et al., "Heuristics for the robust vehicle routing problem with time windows," Expert Syst. Appl., vol. 77, pp. 136-147, Feb 2017.

[19] E. Yuliza and F. M. Puspita, "Branch and Cut Method for Solving Capacitated Vehicle Routing Problem (CVRP) Model of LPG Gas Distribution Routes," Sci. Technol. Indones., vol. 4, no. 4, pp. 105-108, Oct 2019.

[20] A. Agra, et al., "The robust vehicle routing problem with time windows," Comput. Oper. Res., vol. 40, no. 3, pp. 856-866, March 2013.

[21] C. Hu, et al., "Robust vehicle routing problem with hard time windows under demand and travel time uncertainty," Comput. Oper. Res., vol. 94, pp. 139-153, Jun 2018.

[22] T. Manisri, A. Mungwattana, and G. K. Janssens, "Minimax optimisation approach for the Robust Vehicle Routing Problem with Time Windows and uncertain travel times," Int. J. Logist. Syst. Manag., vol. 10, no. 4, pp. 461-477, Oct 2011.

[23] D. Lu and F. Gzara, "The robust vehicle routing problem with time windows: Solution by Branch and Price and Cut," Eur. J. Oper. Res., vol. 275, no. 3, pp. 925-938, Jun 2019.

[24] P. Munari, A. Moreno, J. D. La Vega, D. Alem, J. Gondzio, and R. Morabito, "The robust vehicle routing problem with time windows : compact formulation and branch-price-and-cut method," Oper. Res. Gr., no. Technical Report 002/2018, pp. 1-34, 2018.

[25] N. A. El-sherbeny, "Vehicle routing with time windows: An overview of exact, heuristic and metaheuristic methods," J. Kinh Saud University-Science, vol. 22, no. 3, pp. 123-131, Jul 2010.

[26] G. Desaulniers, B. Madsen, Oli, and S. Ropke, Chapter 5: The Vehicle Routing Problem with Time Windows, pp. 119-159, 2014.

[27] E. Cao, M. Lai, and H. Yang, "Open vehicle routing problem with demand uncertainty and its robust strategies," Expert Syst. Appl., vol. 41, no. 7, pp. 3569-3575, 2014.

[28] Y. Hartono, F. M. Puspita, D. I. Permatasari, and B. Arisha, "LINGO-based on robust counterpart open capacitated vehicle routing problem (RC-OCVRP) model of waste transportation in Palembang," 2018 Int. Conf. Inf. Commun. Technol. ICOIACT 2018, vol. 2018-Jan, pp. 429-435, 2018.

[29] F. M. Puspita, et al., "Robust Counterpart Open Capacitated Vehicle Routing (RC-OCVRP) Model in Optimization of Garbage Transportation in District Sako and Sukarami , Palembang City," Int. J. Electr. Comput. Eng., vol. 8, no. 6, pp. 4382-4390, Dec 2018.

[30] F. M. Puspita, et al., "Model of Demand Robust Counterpart Open Capacitated Vehicle Routing Problem (DRCOCVRP) Simplification by Applying Preprocessing Techniques in Rubbish Controlling in Sematang Borang District, Palembang," E3S Web Conf. 68, vol. 25, pp. 1-6, 2018. 
[31] E. Solano-Charris, C. Prins, and A. C. Santos, "Local search based metaheuristics for the robust vehicle routing problem with discrete scenarios," Appl. Soft Comput. J., vol. 32, pp. 518-531, 2015.

[32] Z. Yao-zhong and X. Song-yan, "Multi-UAV cooperative reconnaissance decision-making based on Lingo," 2017 2nd Asia-Pacific Conference on Intelligent Robot Systems (ACIRS), pp. 210-213, 2017.

[33] B. Liu and N. Jin, "An application of lingo software to solve dynamic programming problem in the field of environmental protection," 2015 IEEE Advanced Information Technology, Electronic and Automation Control Conference (IAEAC), pp. 577-580, 2015.

[34] B. Das and A. Kumar, "Cost optimization of a hybrid energy storage system using GAMS Department of Electrical Engineering," IEEE, pp. 89-92, 2017.

[35] R. Singh and A. Kumar S.M., "Estimation of Off Shore Wind Power Potential and Cost Optimization of Wind Farm in Indian Coastal Region by Using GAMS,"2018 International Conference on Current Trends towards Converging Technologies (ICCTCT), pp. 1-6, 2018.

\section{BIOGRAPHIES OF AUTHORS}

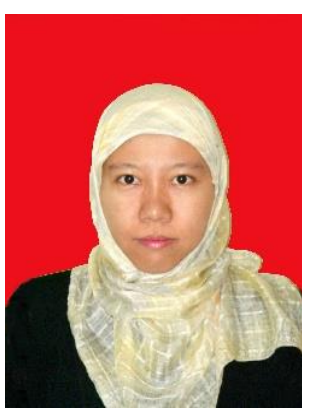

Evi Yuliza her S.Si degree in Mathematics from Sriwijaya University, South Sumatera, Indonesia in 2000. Then she received her M.Si in Mathematics from Gadjah Mada University in 2004. Her research interests includes Algebra. She has been a Mathematics Department member at Faculty mathematics and Natural Sciences Sriwijaya University South Sumatera Indonesia since 2008. Her research interests include optimization such as vehicle routing problem and algebra.

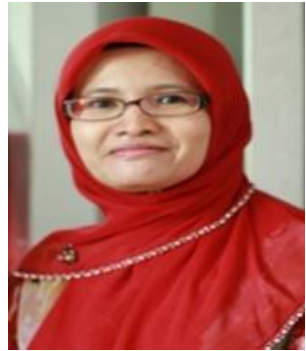

Fitri Maya Puspita received her S.Si degree in Mathematics from Sriwijaya University, South Sumatera, Indonesia in 1997. Then she received her M.Sc in Mathematics from Curtin University of Technology (CUT) Western Australia in 2004. She got her Ph.D from Faculty of Science and Technology Islamic Science University of Malaysia (USIM), Nilai, Negeri Sembilan Darul Khusus, Malaysia in 2015. She has been a Mathematics Department member at Faculty mathematics and Natural Sciences Sriwijaya University South Sumatera Indonesia since 1998. Her research interests include optimization and its applications such as vehicle routing problems and QoS pricing and charging in third generation internet.

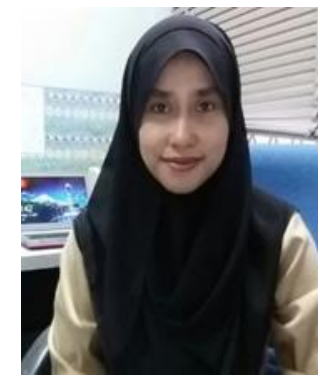

Siti Suzlin Supadi her BSc in Mathematics from University of Malaya in 2001. Then she received her MSc from University of Malaya in 2004 and her research interest is applied mathematics. She got her PhD from University of Malaya in 2012 and her research interest is applied mathematics. She has been a Institute of Mathematical Sciences at Faculty of Science University of Malaya, Kuala Lumpur. Her research interest include operation research (Inventory Modelling, Vendor-Buyer Coordination) 